\title{
Corticosteroid therapy in critical illness due to seasonal and pandemic influenza
}

\author{
Philippe Yale $\mathrm{MD}^{1 *}$, Neill KJ Adhikari MDCM MSc${ }^{2 *}$, Vincent Masse MD ${ }^{1,3}$, Robert A Fowler MDCM MSc${ }^{2}$, \\ Wei Xiong MSc ${ }^{4}$, Allison McGeer MD FRCPC ${ }^{5}$, Darlene Cann RN5 , Wallis Rudnick MSc ${ }^{5}$, Karen Green $\mathrm{RN} \mathrm{MSc}^{5}$, \\ Maureen O Meade MD MSc ${ }^{6}$, Louis Valiquette $\mathrm{MD}^{1,3}$, François Lamontagne MD MSc ${ }^{1}$
}

P Yale, NKJ Adhikari, V Masse, et al. Corticosteroid therapy in critical illness due to seasonal and pandemic influenza. Can Respir J 2015;22(5):271-274.

BACKGROUND: Survey data suggest that Canadian intensivists administer corticosteroids to critically ill patients primarily in response to airway obstruction, perceived risk for adrenal insufficiency and hemodynamic instability.

OBJECTIVE: To describe variables independently associated with systemic corticosteroid therapy during an influenza outbreak.

METHODS: The present analysis was retrospective cohort study involving critically ill patients with influenza in two Canadian cities. Hospital records were reviewed for critically ill patients treated in the intensive care units (ICUs) of eight hospitals in Canada during the 2008 to 2009 and 2009 to 2010 influenza outbreaks. Abstracted data included demographic information, symptoms at disease onset, chronic comorbidities and baseline illness severity scores. Corticosteroid use data were extracted for every ICU day and expressed as hydrocortisone dose equivalent in $\mathrm{mg}$. Multivariable regression models were constructed to identify variables independently associated with corticosteroid therapy in the ICU.

RESULTS: The study cohort included 90 patients with a mean $( \pm$ SD) age of $55.0 \pm 17.3$ years and Acute Physiology and Chronic Health Evaluation II score of $19.8 \pm 8.3$. Patients in 2009 to 2010 were younger with more severe lung injury but similar exposure to corticosteroids. Overall, $54 \%$ of patients received corticosteroids at a mean daily dose of $343 \pm 330 \mathrm{mg}$ of hydrocortisone for $8.5 \pm 4.8$ days. Variables independently associated with corticosteroid therapy in the ICU were history of airway obstruction (OR 4.8 [95\% CI 1.6 to 14.9$]$ ) and hemodynamic instability (OR 4.6 [95\% CI 1.2 to 17.8$]$ ).

CONCLUSION: Observational data revealed that hemodynamic instability and airway obstruction were associated with corticosteroid therapy in the critical care setting, similar to a recent survey of stated practice. Efforts to determine the effects of corticosteroids in the ICU for these specific clinical situations are warranted.

Key Words: Cohort study; Corticosteroids; Critical illness; Influenza; Intensive care unit; Pandemic H1N1; Seasonal influenza

$\mathrm{R}$ ecent survey data suggest that septic shock, airway obstruction Rand perceived risk for adrenal insufficiency underlie intensivists' prescription of corticosteroids (1). Understanding what illnesses trigger corticosteroid therapy in the intensive care unit (ICU) is relevant because recent data suggest corticosteroids may harm patients with some of these conditions. For example, in recent observational studies, the use of corticosteroids in the context of acute exacerbations of chronic obstructive pulmonary disease (COPD) was associated with an increased risk for death (2,3). As evidence accumulates on the risks and benefits of corticosteroid therapy in critically ill patients, understanding what triggers its use is a quality of care necessity.

The 2009 influenza A (H1N1) pandemic caused severe hypoxemic respiratory failure in many patients who required ICU care (4). Shock

\section{La corticothérapie en cas de grave maladie secondaire à la grippe saisonnière ou pandémique}

HISTORIQUE : Selon les données d'enquête, les intensivistes canadiens administrent surtout des corticoïdes aux patients gravement malades en cas d'obstruction des voies respiratoires, d'un risque perçu d'insuffisance surrénalienne et d'instabilité hémodynamique.

OBJECTIF : Décrire les variables associées de manière indépendante à la corticothérapie systémique pendant une éclosion de grippe.

MÉTHODOLOGIE : La présente étude de cohorte rétrospective portait sur des patients gravement malades à cause d'une grippe dans deux villes canadiennes. Les chercheurs ont examiné les dossiers hospitaliers de patients gravement malades traités à l'unité de soins intensifs (USI) de huit hôpitaux du Canada pendant les éclosions de grippe de 2008 à 2009 et de 2009 à 2010. Les données résumées incluaient des renseignements démographiques, les symptômes à l'apparition de la maladie, les comorbodités chroniques et les indices de gravité au début de la maladie. Les chercheurs ont extrait les données d'utilisation de la corticothérapie chaque jour à l'USI et les ont converties en milligrammes de dose d'hydrocortisone équivalente. Ils ont construit des modèles de régression multivariable pour déterminer les variables associées de manière indépendante à la corticothérapie à l'USI.

RÉSULTATS : L'étude de cohorte incluait 90 patients d'un âge moyen ( \pm ÉT) de $55,0 \pm 17,3$ ans et le score de l'évaluation physiologique aiguë et de l'évaluation de la santé chronique II de 19,8 $\pm 8,3$. En 2009 et 2010, les patients étaient plus jeunes et avaient des lésions pulmonaires plus graves, mais étaient exposés aux corticoïdes de manière similaire. Dans l'ensemble, $54 \%$ des patients ont reçu des corticoïdes à une dose quotidienne moyenne de $343 \pm 330 \mathrm{mg}$ d'hydrocortisone pendant $8,5 \pm 4,8$ jours. Les variables associées de manière indépendante à la corticothérapie à l'USI étaient des antécédents d'obstruction des voies respiratoires (rapport de cotes [RC] 4,8 [95\% IC 1,6 à 14,9]) et une instabilité hémodynamique (RC 4,6 [95 \% IC 1,2 à 17,8]). CONCLUSION : Les données d'observation ont révélé que l'instabilité hémodynamique et l'obstruction des voies respiratoires s'associaient à une corticothérapie à l'USI, comme dans une récente enquête sur les pratiques établies. Il faudra faire des efforts pour déterminer les effets de la corticothérapie dans ces situations cliniques à l'USI.

was also frequent, as suggested by $32.7 \%$ of patients who received vasopressors on the first day in the ICU (4). Despite limited evidence of efficacy or safety, $50 \%$ of critically ill patients with A(H1N1)pdm09 influenza received systemic corticosteroids (4). The reasons for corticosteroid therapy in these patients have not been described; however, observational data published since the 2009 pandemic have associated corticosteroid therapy with increased risk for death in this population (3). The high rates of corticosteroid use during the 2009 influenza outbreak may be context specific. Alternatively, they may be explained by the co-occurrence of shock, severe hypoxemia, and other acute or chronic comorbidities. Accordingly, influenza-related critical illness offers an opportunity to study triggers for corticosteroid therapy in the ICU.

\footnotetext{
*Authors who contributed equally

${ }^{1}$ Centre de Recherche Clinique du Centre Hospitalier Universitaire de Sherbrooke (CRCHUS), Université de Sherbrooke, Sherbrooke, Quebec; ${ }^{2}$ Department of Critical Care Medicine, Sunnybrook Health Sciences Centre, Interdepartmental Division of Critical Care, University of Toronto, Toronto, Ontario;

${ }^{3}$ Department of Microbiology $\mathcal{E}$ Infectious Diseases, Université de Sherbrooke, Sherbrooke, Sherborooke, Quebec; ${ }^{4}$ Trauma, Emergency $\mathcal{E}$ Critical Care

Program, Sunnybrook Health Sciences Centre; ${ }^{5}$ Toronto Invasive Bacterial Diseases Network; Department of Microbiology, Mount Sinai Hospital, Toronto, Ontario; ${ }^{6}$ Department of Medicine, Health Sciences Centre, McMaster University, Hamilton, Ontario

Correspondence: Dr François Lamontagne, Service de médecine, Centre Hospitalier Universitaire de Sherbrooke, 12e avenue Nord, Sherbrooke, Québec J1H 5N4. Telephone 819-346-1110, fax 819-820-6406, e-mail francois.lamontagne@usherbrooke.ca
} 
The primary objective of the present study was to identify variables associated with corticosteroid prescription in critically ill patients infected with influenza. A secondary objective was to compare the clinical presentation of patients infected with influenza A (H1N1) pdm09 versus seasonal influenza from a previous outbreak.

\section{METHODS}

\section{Setting}

All critically ill patients during the 2008 to 2009 and 2009 to 2010 influenza outbreaks treated in eight hospitals in two Canadian cities (Sherbrooke [Quebec] and Toronto [Ontario]) were included. Eight centres were selected in which retrospective collection of additional relevant data not included in the two existing databases used for the present study was possible. These centres are the Toronto General Hospital, Toronto Western Hospital, Mount Sinai Hospital, Toronto East General Hospital, St Michael's Hospital, North York General Hospital, Centre Hospitalier Universitaire de Sherbrooke - Hôtel-Dieu and Centre Hospitalier Universitaire de Sherbrooke - Fleurimont.

\section{Patient eligibility}

Specific eligibility criteria were age $>16$ years; critical illness defined by admission to an ICU; and confirmed influenza infection according to case definitions developed by the WHO and the Canadian National Microbiology Laboratory (4). All patients who had confirmed or probable influenza A(H1N1)pdm09 infection during the 2009 to 2010 outbreak were included. Influenza subtypes for 2008 to 2009 were not collected.

\section{Data collection}

Baseline demographic data, symptoms at disease onset, chronic comorbidities, including history of obstructive airways disease (asthma or COPD), and history of home corticosteroid therapy (as described in medical histories from charts) and illness severity scores at the time of ICU admission were collected. In addition to Acute Physiology and Chronic Health Evaluation (APACHE) II score (5), a threevariable lung injury score (LIS) (6) was calculated, excluding lung compliance (not available) and the Sequential Organ Failure Assessment (SOFA) score (7) for ICU days 1, 2, 3, 7 and 14, in which day 1 referred to the day of ICU admission. Corticosteroid use data (specific drug and equivalent dose in $\mathrm{mg}$ of hydrocortisone) were extracted for every ICU day.

Data from two existing databases were harmonized. The first database was created at the beginning of the $2009 \mathrm{H} 1 \mathrm{~N} 1$ pandemic in Canada and contained data for 168 critically ill patients with confirmed or probable influenza $A(\mathrm{H} 1 \mathrm{~N} 1) \mathrm{pdm09}$, including those from Sherbrooke and Toronto (4). Data regarding critically ill patients with seasonal influenza in 2008 to 2009 were extracted from the Toronto Invasive Bacterial Diseases Network database for six Toronto centres (8). Information regarding variables not captured in these databases (corticosteroid use, APACHE II, SOFA and LIS scores) and data regarding patients infected with seasonal influenza in 2008 to 2009 in Sherbrooke were extracted directly from patient charts. Data were compiled in Excel (Microsoft Corporation, USA) and analyzed using SAS version 9.3 (SAS Institute, USA).

\section{Statistical analysis}

Continuous variables are described using means and SD and categorical data using counts (percentages).

A logistic regression model was constructed to measure associations of eight independent variables with corticosteroid therapy in the ICU. Under the assumption that approximately $50 \%$ of patients would receive corticosteroids, a multivariable model with $>5$ events per variable was planned to ensure statistical stability (9). The following independent variables, predefined and selected on the basis of plausible associations with corticosteroid prescriptions, were entered in the model simultaneously: age, year of influenza outbreak (2008 to 2009 versus 2009 to 2010), asthma or COPD, and ICU admission APACHE II score, day 1 LIS $>2.5$, day 1 cardiovascular SOFA score $>1$, outpatient corticosteroid use and city (Toronto versus Sherbrooke, to account for city-specific practice patterns). The values at which the LIS and cardiovascular SOFA scores were dichotomized represented severe lung injury (6) and any need for vasopressors (7), respectively.

A sensitivity analysis was conducted by entering the day 1 LIS and cardiovascular SOFA scores as continuous variables. No collinearity between history of asthma or COPD and history of corticosteroid use was found (variance inflation factor 1.055). Accordingly, both variables were kept in the multivariable model. Plots of log odds versus continuous independent variables showed no violations of the assumption of a linear realtionship. Goodness of fit was examined using the Hosmer-Lemeshow test.

All univariable comparisons between groups were conducted using independent Student's $t$ tests for continuous variables, and $\chi^{2}$ or Fisher's exact test for dichotomous variables.

\section{Ethics}

The Research Ethics Board of the Centre Hospitalier Universitaire de Sherbrooke (protocol number 10-195) reviewed this protocol and waived the requirement for patient consent. Data collection for Toronto Invasive Bacterial Diseases Network cases was previously approved by the research ethics boards of all participating institutions.

\section{Patients}

\section{RESULTS}

Ninety patients ( $\mathrm{n}=25$ from the 2008 to 2009 outbreak and $n=65$ from the 2009 to 2010 outbreak) were included from the eight sites $(n=32$ from Sherbrooke, $n=58$ from Toronto). Overall, 42 (46.7\%) patients were female (mean age $55 \pm 17$ years) and the mean APACHE II score was $19.8 \pm 8.3$. However, patients with influenza $A(H 1 N 1)$ pdm09 during the 2009 to 2010 pandemic were younger by a mean of 11 years and tended to have more severe lung injury and organ dysfunction at baseline compared with those with seasonal influenza in 2008 to 2009 (Table 1). The highest LIS in ICU was also higher in patients infected with influenza $\mathrm{A}(\mathrm{H} 1 \mathrm{~N} 1)$ pdm09 (2.6 \pm 1.1 versus $1.6 \pm 1.1 ; \mathrm{P}=0.0004)$. There was no difference in case fatality rates (A[H1N1]pdm09 17 of 65 [26\%], seasonal five of 25 [20\%]; $\mathrm{P}=0.54$ ).

\section{Corticosteroid use in ICU}

Comparing patients with $\mathrm{pH} 1 \mathrm{~N} 1$ and seasonal influenza, the proportion who received systemic corticosteroids while in ICU was not different $(52.3 \%$ versus $60.0 \%$ ) (Table 2 ). No difference was observed in the duration, cumulative dose and average daily dose of corticosteroids between the two groups or when limited to patients without a history of corticosteroid use. Patients who received corticosteroids were treated for $4.6 \pm 5.5$ days, for a cumulative dose of $1548 \pm 2693 \mathrm{mg}$ of hydrocortisone and an average daily dose of $187 \pm 297 \mathrm{mg}$. Overall, 32 of $43(74.4 \%)$ patients with a history of obstructive airways disease, nine of $28(32.1 \%)$ with a day 1 LIS score $>2.5,15$ of $24(62.5 \%)$ with a day 1 cardiovascular SOFA score $>1$, and 12 of 15 (80.0\%) with a history of outpatient corticosteroid use received systemic corticosteroids in the ICU. Eleven (25.6\%) of 43 patients with a history of asthma or COPD also had a history of home corticosteroid use. Conversely, 11 of $15(73.3 \%)$ patients with a history of outpatient corticosteroid use also had a history of asthma or COPD.

Variables associated with costicosteroid use in univariable analyses were history of asthma or COPD, day 1 LIS $>2.5$ and history of home corticosteroid use. In multivariable analyses, the only independently associated variables were day 1 cardiovascular SOFA score $>1$ (adjusted OR 4.59 [95\% CI 1.19 to 17.77]) and history of obstructive airway disease (adjusted OR 4.80 [95\% CI 1.55 to 14.88) (Table 3).

\section{DISCUSSION}

Our results suggest that the triggers for corticosteroid therapy in ICU were a history of asthma or COPD and hemodynamic instability, but not the presence of severe lung injury. These clinical triggers for corticosteroid prescription in patients with severe viral lung infections 
TABLE 1

\section{Baseline characteristics}

\begin{tabular}{|c|c|c|c|c|}
\hline & \multicolumn{4}{|c|}{ Patients } \\
\hline & All $(n=90)$ & $\begin{array}{c}2008-2009 \\
\text { seasonal } \\
\text { influenza } \\
(n=25)\end{array}$ & $\begin{array}{c}2009-2010, \\
\text { influenza } \\
A(H 1 N 1) \\
\text { pdm09 } \\
(n=65)\end{array}$ & $\mathbf{P}$ \\
\hline Age, mean \pm SD & $55 \pm 17.2$ & $63 \pm 17.3$ & $52 \pm 16.4$ & 0.008 \\
\hline Female sex & $42(46.7)$ & $14(56.0)$ & $28(43.1)$ & 0.27 \\
\hline $\begin{array}{l}\text { History of outpatient } \\
\text { corticosteroid use }\end{array}$ & $15(16.7)$ & $3(12.0)$ & $12(18.5)$ & 0.54 \\
\hline History of diabetes & $24(26.7)$ & $6(24.0)$ & $18(27.7)$ & 0.72 \\
\hline History of hypertension & $39(43.3)$ & $14(56.0)$ & $25(38.5)$ & 0.13 \\
\hline $\begin{array}{l}\text { History of coronary artery } \\
\text { disease }\end{array}$ & $16(17.8)$ & $8(32.0)$ & $8(12.3)$ & 0.06 \\
\hline History of renal failure & $5(5.6)$ & $3(12.0)$ & $2(3.1)$ & 0.13 \\
\hline History of cancer & $9(10.0)$ & $2(8.0)$ & $7(10.8)$ & 1.00 \\
\hline History of asthma or COPD & $43(47.8)$ & $12(48.0)$ & $31(47.7)$ & 0.98 \\
\hline APACHE II score, mean \pm SD & $19.8 \pm 8.3$ & $20.3 \pm 7.3$ & $19.7 \pm 8.7$ & 0.76 \\
\hline LIS, mean \pm SD & $2.0 \pm 1.1$ & $1.5 \pm 1.0$ & $2.3 \pm 1.1$ & 0.005 \\
\hline LIS $>2.5$ & $28(31.1)$ & $4(16.0)$ & $24(36.9)$ & 0.055 \\
\hline Total SOFA score, mean \pm SD & $7.0 \pm 3.8$ & $5.8 \pm 3.5$ & $7.5 \pm 3.9$ & 0.058 \\
\hline $\begin{array}{l}\text { Cardiovascular SOFA score, } \\
\text { mean } \pm \text { SD }\end{array}$ & $0.96 \pm 1.4$ & $1.0 \pm 1.4$ & $0.9 \pm 1.4$ & 0.73 \\
\hline Cardiovascular SOFA score $>1$ & $24(26.7)$ & $7(28.0)$ & $17(26.2)$ & 0.86 \\
\hline
\end{tabular}

Data presented as $n$ (\%) unless otherwise indicated. All scores are from intensive care unit admission. APACHE Acute Physiology and Chronic Health Evaluation; COPD Chronic obstructive pulmonary disease; LIS Lung injury score; SOFA Sequential Organ Failure Assessment

were not specific to the 2009 influenza outbreak. Moreover, they are consistent with self-reported triggers in other critically ill patients (1).

Our data were obtained from 90 patients infected with influenza treated in ICUs from two Canadian cities in 2008 and 2009. Accordingly, the applicability of the results may be limited in space and time, and statistical power may be insufficient to detect certain variables independently associated with corticosteroid use, such as outpatient corticosteroid use. Moreover, because the present study did not involve clinician interviews or abstraction of clinical reasoning from progress notes, we cannot determine whether hemodynamic instability or acute bronchospasm specifically triggered the prescription of corticosteroids on a particular day. However, our results are concordant with those obtained in a recent survey involving 103 intensivists from Canada and the United States who stated that bronchospasm and shock (with or without previous exposure to corticosteroids) justified corticosteroid therapy for critically ill patients (1). In the survey, intensivists did not identify lung injury as a justification for systemic corticosteroid therapy. As in any retrospective study, data collection may be limited by incomplete medical records. However, key variables, such as prescription of corticosteroids in the ICU, are unlikely to be missing. As for variables that may be less well documented, such as home use of corticosteroids, missing data most likely occurred at random and is an unlikely source of bias. Although we cannot completely exclude between-centre differences in steroid prescribing practices, adjusting for the city did not alter the results. Finally, by design, the present study did not address the effect of corticosteroids on clinical outcomes. Experimental data that provide useful information about the efficacy and safety of corticosteroids in critical illness already exist. Any remaining uncertainty should be identified from accurate descriptions of usual practices (as reported herein) and a comprehensive critical appraisal of existing studies. More observational data could only add to the confusion because it would be insufficient to refute existing clinical trials and any new observation would require confirmation in a clinical trial.
TABLE 2

Description of corticosteroid use

\begin{tabular}{llccc}
\hline & \multicolumn{4}{c}{ Patients } \\
\cline { 2 - 4 } & All (n=90) & $\begin{array}{c}\text { 2008-2009, } \\
\text { seasonal } \\
\text { influenza } \\
(\mathbf{n = 2 5})\end{array}$ & $\begin{array}{c}\text { 2009-2010, } \\
\text { influenza } \\
\text { A(H1N1) } \\
\text { pdm09 } \\
(\mathbf{n}=65)\end{array}$ & P \\
\hline $\begin{array}{c}\text { Patients who received } \\
\text { any corticosteroid } \\
\text { during ICU stay, } \mathrm{n}(\%)\end{array}$ & $49(54.4)$ & $15(60.0)$ & $34(52.3)$ & 0.51 \\
$\begin{array}{c}\text { Days on } \\
\text { corticosteroids }\end{array}$ & $4.6 \pm 5.5$ & $5.3 \pm 5.1$ & $4.4 \pm 5.7$ & 0.49 \\
$\begin{array}{c}\text { Cumulative dose of } \\
\text { corticosteroids, } \\
\text { equivalent mg of } \\
\text { hydrocortisone }\end{array}$ & $1548 \pm 2693$ & $2120 \pm 3496$ & $1328 \pm 2308$ & 0.30 \\
$\begin{array}{c}\text { Average daily dose } \\
\text { of corticosteroids; } \\
\text { equivalent mg of } \\
\text { hydrocortisone }\end{array}$ & $187 \pm 297$ & $244 \pm 381$ & $164 \pm 257$ & 0.34 \\
\hline
\end{tabular}

Data presented as mean $\pm S D$ unless otherwise indicated. ICU Intensive care unit

Safe medication practices imply that benefits associated with specific interventions outweigh their risks. The conditions most strongly associated with corticosteroid use are common in ICUs and relevant outside the context of specific infectious outbreaks. With concordant data from surveys and the present observational study, the practice patterns of Canadian intensivists with regard to the administration of corticosteroids are clear. Clinicians and quality improvement experts may now more specifically examine whether the reported risks of this therapy warrant interventions to modify current practices. If not, then our findings lend support to more focused research of the effects of corticosteroids in patients with hemodynamic instability (NCT01448109) or airway obstruction (2). In COPD exacerbations, their benefit corresponds to improvements in surrogate outcomes that do not apply to critically ill patients who are already mechanically ventilated (eg, forced expiratory volumes, blood gases) (10). Our results may also guide the design of future trials because investigators may be interested in knowing that patients with hemodynamic instability and airway obstruction, but not severe lung injury, are more likely to receive corticosteroids under usual care. In addition, clinicians interpreting the results of future trials of corticosteroids for shock will devote attention to the chronic comorbidities profile of enrolled patients to determine if and how the results apply to their patients.

ACKNOWLEDGEMENTS: This study was conducted on behalf of the Canadian Critical Care Trials Group (CCCTG). For the duration of this work, François Lamontagne and Maureen Meade held a Canadian Institutes of Health Research (CIHR) Randomized Controlled Trials Mentoring Award. François Lamontagne holds a research career award from the Fonds de la Recherche du Québec - Santé (FRQS).

DISCLOSURES: All authors declare that they have no significant competing financial, professional and/or personal interests that may have influenced the performances or presentation of the work described in this article.

AUTHOR CONTRIBUTIONS: Philippe Yale: Substantial contributions to the conception and design of the work and the acquisition of data and drafting the work and final approval of the version to be published; Neill KJ Adhikari: Substantial contributions to the analysis and interpretation of data for the work and revising the manuscript critically for important intellectual content and final approval of the version to be published; Vincent Masse: Substantial contributions to the conception 
TABLE 3

Variables associated with corticosteroid use

\begin{tabular}{|c|c|c|c|c|}
\hline & \multicolumn{2}{|c|}{ Patients treated with corticosteroids } & \multicolumn{2}{|c|}{ OR $(95 \% \mathrm{Cl})$} \\
\hline & Yes $(n=49)$ & No $(n=41)$ & Univariable & Multivariable \\
\hline Age, years, mean $\pm S D$ & $57 \pm 17$ & $52 \pm 17$ & $1.02(0.996-1.05)$ & $1.001(0.97-1.03)^{*}$ \\
\hline APACHE II score, mean \pm SD & $19.6 \pm 8.3$ & $20.2 \pm 8.3$ & $0.99(0.94-1.04)$ & $0.97(0.90-1.04)^{\dagger}$ \\
\hline Asthma or COPD $\ddagger$ & $32(65.3)$ & $11(26.8)$ & $5.13(2.07-12.72)$ & $4.80(1.55-14.88)$ \\
\hline Day 1 Lung Injury Score $>2.5^{\ddagger}$ & $9(18.4)$ & $19(46.3)$ & $0.26(0.10-0.67)$ & $0.41(0.13-1.36)$ \\
\hline Day 1 cardiovascular SOFA score $>1 \ddagger$ & $15(30.6)$ & $9(22.0)$ & $1.57(0.60-4.08)$ & $4.59(1.19-17.77)$ \\
\hline Sherbrooke, Quebec (versus Toronto, Ontario) $)^{\ddagger}$ & $17(34.7)$ & $15(36.6)$ & $0.92(0.39-2.19)$ & $0.62(0.21-1.84)$ \\
\hline
\end{tabular}

Data presented as $n(\%)$ unless otherwise indicated. "OR per one-year increase; †OR per one-point increase in Acute Physiology and Chronic Health (APACHE) II score; ¥Percentages represent proportion of patients with this independent variable. SOFA Sequential Organ Failure Assessment

and design of the work and the acquisition of data and drafting the work and final approval of the version to be published; Robert A Fowler: Substantial contributions to the conception and design of the work and the analysis and interpretation of data for the work and revising the manuscript critically for important intellectual content and final approval of the version to be published; Wei Xiong: Substantial contributions to the analysis and interpretation of data for the work and revising the manuscript critically for important intellectual content and final approval of the version to be published; Allison McGeer: Substantial contributions to the conception and design of the work and the acquisition of data and revising the manuscript critically for important intellectual content and final approval of the version to be published; Darlene Cann: Substantial contributions to the conception and design of the work and the acquisition of data and revising the manuscript critically for important intellectual content and final approval of the version to be published; Wallis Rudnick: Substantial contributions to the conception and design of the work and the acquisition of data and revising the manuscript critically for

\section{REFERENCES}

1. Lamontagne F, Quiroz Martinez H, Adhikari NK, et al. Corticosteroid use in the intensive care unit: A survey of intensivists. Can J Anaesth 2013;60:652-9.

2. Kiser TH, Allen RR, Valuck RJ, Moss M, Vandivier RW. Outcomes associated with corticosteroid dosage in critically ill patients with acute exacerbations of chronic obstructive pulmonary disease. Am J Respir Crit Care Med 2014;189:1052-64.

3. Martin-Loeches I, Lisboa T, Rhodes A, et al. Use of early corticosteroid therapy on ICU admission in patients affected by severe pandemic $(\mathrm{H} 1 \mathrm{~N} 1) \mathrm{v}$ influenza $\mathrm{A}$ infection. Intens Care Med 2011;37:272-83.

4. Kumar A, Zarychanski R, Pinto R, et al. Critically ill patients with 2009 influenza $\mathrm{A}(\mathrm{H} 1 \mathrm{~N} 1)$ infection in Canada. JAMA 2009;302:1872-9.

5. Knaus WA, Draper EA, Wagner DP, Zimmerman JE. APACHE II: A severity of disease classification system. Crit Care Med 1985; 13:818-29. important intellectual content and final approval of the version to be published; Karen Green: Substantial contributions to the conception and design of the work and the acquisition of data and revising the manuscript critically for important intellectual content and final approval of the version to be published; Maureen Meade: Substantial contributions to the conception and design of the work and the analysis and interpretation of data for the work and revising the manuscript critically for important intellectual content and final approval of the version to be published; Louis Valiquette: Substantial contributions to the conception and design of the work and the analysis and interpretation of data for the work and revising the manuscript critically for important intellectual content and final approval of the version to be published; François Lamontagne: Substantial contributions to the conception or design of the work, its analysis and interpretation of data for the work and drafting the work and revising it critically for important intellectual content final approval of the version to be published.

6. Murray JF, Matthay MA, Luce JM, Flick MR. An expanded definition of the adult respiratory distress syndrome.

Am Rev Respir Dis 1988;138:720-3.

7. Vincent JL, Moreno R, Takala J, et al. The SOFA (Sepsis-related Organ Failure Assessment) score to describe organ dysfunction/ failure. On behalf of the Working Group on Sepsis-Related Problems of the European Society of Intensive Care Medicine. Intens Care Med 1996;22:707-10.

8. Davies HD, McGeer A, Schwartz B, et al. Invasive group A streptococcal infections in Ontario, Canada. Ontario Group A Streptococcal Study Group. N Engl J Med 1996;335:547-54.

9. Vittinghoff E, McCulloch CE. Relaxing the rule of ten events per variable in logistic and Cox regression. Am J Epidemiol 2007; $165: 710-8$.

10. Abroug F, Ouanes I, Abroug S, et al. Systemic corticosteroids in acute exacerbation of COPD: A meta-analysis of controlled studies with emphasis on ICU patients. Ann Intens Care 2014;4:32. 


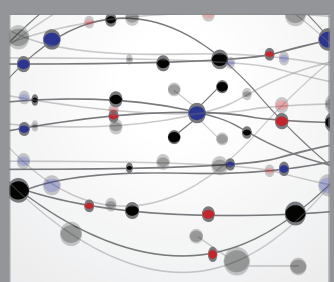

The Scientific World Journal
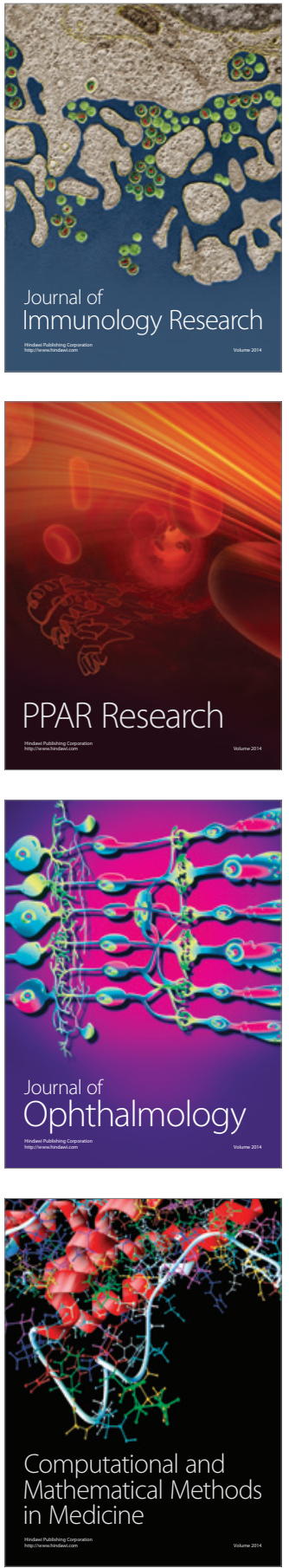

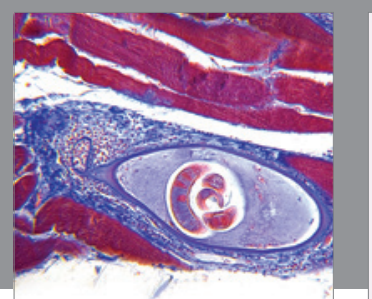

Gastroenterology Research and Practice

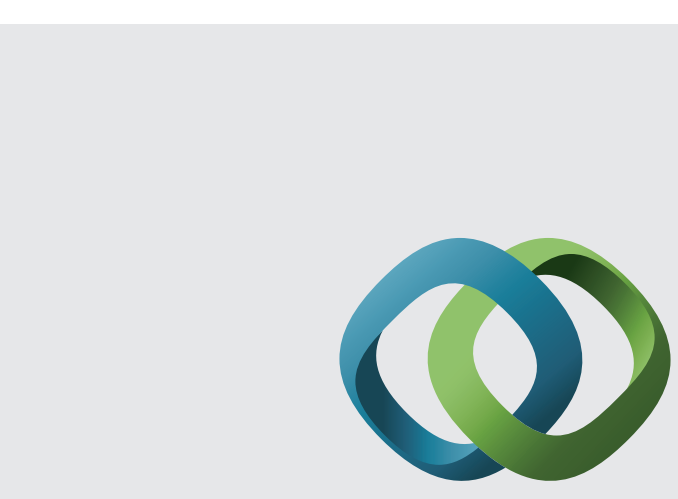

\section{Hindawi}

Submit your manuscripts at

http://www.hindawi.com
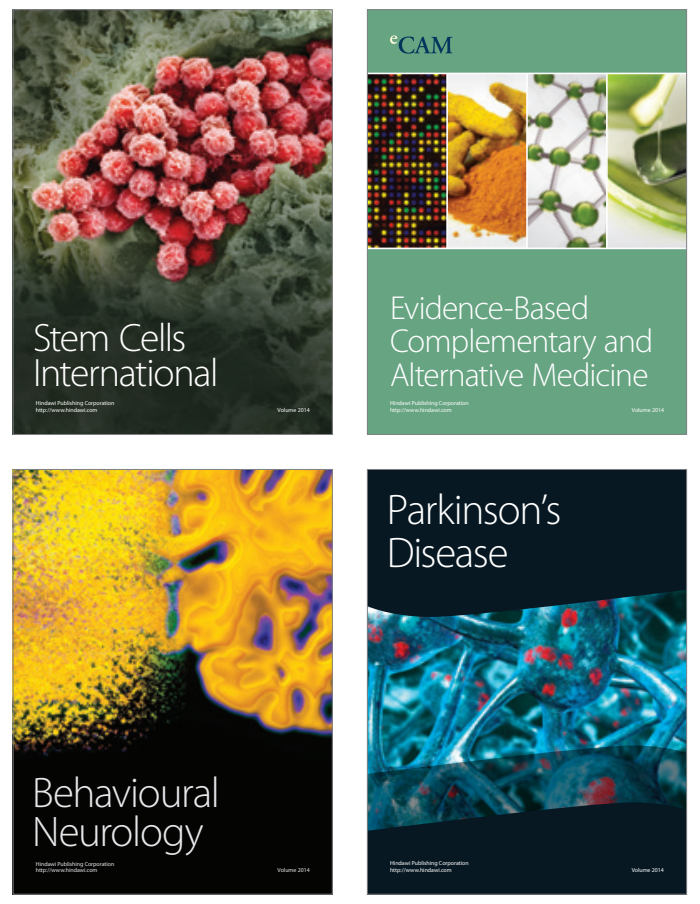
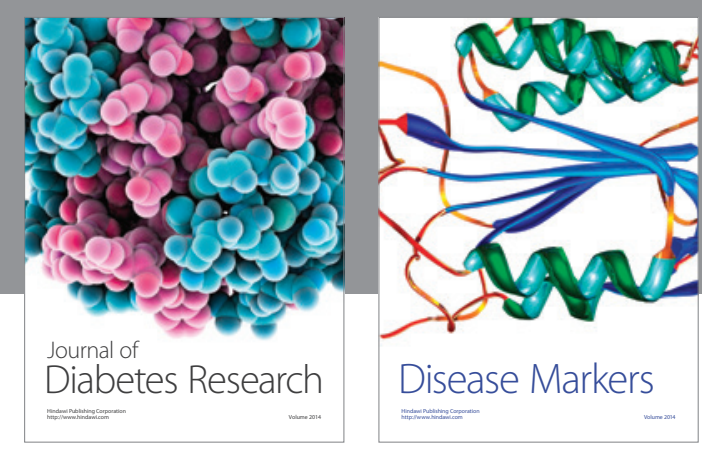

Disease Markers
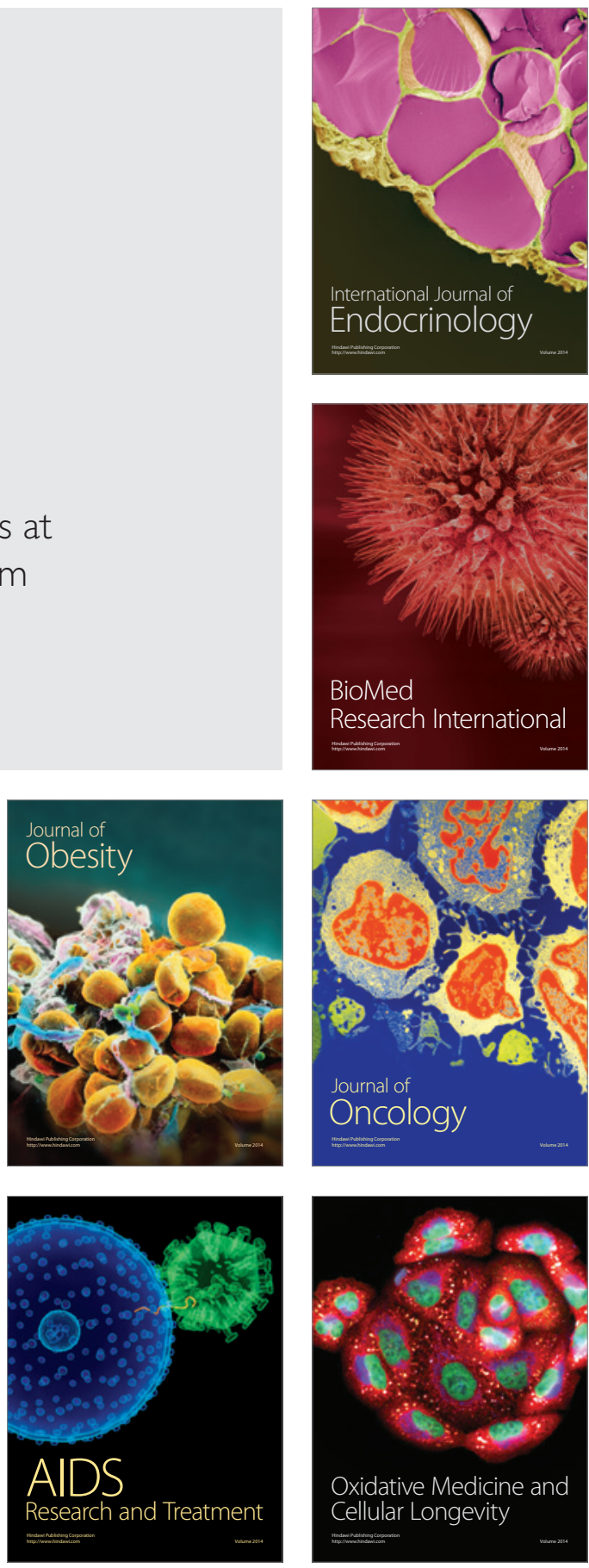